\title{
DEVELOPMENT OF A VALIDATED STABILITY INDICATING LC-MS METHOD FOR THE DETERMINATION OF TENOFOVIR DISOPROXIL FUMARATE USING QUALITY BY DESIGN APPROACH
}

\author{
CHANDNI SAHA $^{1}{ }^{*}$, N. VISHAL GUPTA ${ }^{1}$, R. S. CHANDAN ${ }^{2}$, SHANMUKHA PRIYA P. $^{3}$
}

1Department of Pharmaceutics, JSS College of Pharmacy, JSS Academy of Higher Education \& Research, Mysuru, Karnataka 570015, India, 2Department of Pharmaceutical Chemistry, JSS College of Pharmacy, JSS Academy of Higher Education \& Research, Mysuru, Karnataka 570015, India, ${ }^{3}$ Department of Chemistry, Institution of Excellence, University of Mysore, 570006

Email: chandnisaha7@gmail.com

Received: 10 Feb 2019, Revised and Accepted: 01 Jun 2019

\section{ABSTRACT}

Objective: To develop a validated Liquid Chromatography-Mass Spectrometry (LC-MS) method through Quality by Design (QbD) approach for the determination of tenofovir disoproxil fumarate (tenofovir DF) in bulk, pharmaceutical formulation and stress conditions.

Methods: The analytical target profile (ATP) was to develop a simple, accurate, precise, specific, and robust method with the Critical Quality Attribute (CQA) being retention time, theoretical plate and peak tailing. Derived from the risk assessment studies, four high-risk factors were screened using resolution V irregular fraction design. Organic modifier strength, flow rate and injection volume were further optimized using BoxBehnken design (BBD). The optimized method condition was validated and applied for the determination of the analyte in pharmaceutical formulation. The stability of the analyte in stress conditions was determined. All experiments were performed using reverse-phase Acquity UPLC BEH C18 $(1.7 \mu \mathrm{m}, 1 \mathrm{~mm}$ X $50 \mathrm{~mm})$ column coupled in-line with Synapt G2 mass spectrometer in positive electrospray ionization (ESI) mode with electron multiplier analog-to-digital detector.

Results: Optimized method condition eluted analyte at $3.40 \mathrm{~min}$ and the $\mathrm{m} / \mathrm{z} 520$ ratified the analyte peak. The method was validated and was found to be specific, linear in the range of $20-100 \mu \mathrm{g} / \mathrm{ml}\left(\mathrm{R}^{2}=0.9998\right)$ with accuracy between $98.71 \%-101.17 \%$ and precise. The limit of detection and quantification were $5.50 \mu \mathrm{g} / \mathrm{ml}$ and $16.68 \mu \mathrm{g} / \mathrm{ml}$ respectively. Analyte degraded completely in acid and basic environment, however, stable in oxidative and photolytic conditions.

Conclusion: The validated method developed through the systematic and rational QbD approach bespoke superior quality. The QbD approach not only justified the entire process but also eliminated uncertainties.

Keywords: Box-Behnken design, LC-MS, Method development QbD, Resolution V irregular fraction design, Tenofovir disoproxil fumarate, Validation

(C) 2019 The Authors. Published by Innovare Academic Sciences Pvt Ltd. This is an open access article under the CC BY license (http://creativecommons.org/licenses/by/4.0/] DOI: http://dx.doi.org/10.22159/ijap.2019v11i4.32500

\section{INTRODUCTION}

The ascendency of the pharmaceutical industry rest on the quality it furnishes. The persistent challenge to produce quality products, additionally encompassed by distinct regulatory guidelines propels the pharmaceutical setup to dispense an efficient process from inception. Today, multivariate knowledge and assured quality are obligatory for the approvals from the regulatory bodies [1]. More than a decade ago, Woodcock had briefed on the exigency of consensus pharmaceutical quality definition and U. S. Food Drug Administration's (USFDA) toil towards establishing stringent quality norms through current good manufacturing practices (cGMP) [2]. Endeavors in this direction led International Council for Harmonization of Technical Requirements for Pharmaceuticals for Human Use (ICH) and USFDA institutionalize the principles of QbD into chemical manufacturing control (CMC) review pilot program in 2004 and years later into ICH Q8-Q10 guidelines [3]. QbD, a desideratum for the quality establishment, functions with predefined objectives to be achieved by controlling the CQA through the identification of critical material parameters (CMP) and critical process parameters (CPP) also, using screening and optimizing tools in an iterative manner to discharge competent optimized quality accessible to continuous improvement [4]. Over the years principles of QbD has been predominantly implemented in the pharmaceutical manufacturing process however, Frederick G. Vogt extensively delineated the applications of QbD to analytical methods [5]. Additionally, well-defined statistical tools have also slid into mass spectrometry for modeling and optimization of response variables [6] yet, ceaseless application of $\mathrm{QbD}$ in analytical method development is seldom practiced. Ergo, the systematic application of $\mathrm{QbD}$ to method development is demonstrated in this paper.
Tenofovir DF, an ester prodrug of tenofovir, a nucleotide reverse transcriptase inhibitor (NRTI) was synthesized to overcome the poor absorption of tenofovir from the intestine, enhancing the bioavailability, also, effectively reducing viral load in human immunodeficiency virus HIV infected patients [7]. Despite becoming an integral part of several once-daily combinations of antiretroviral therapy (ART) regimes [8-11], tenofovir DF is associated weakly with the reduction in bone mineral density [12] and neural stem cells [13] besides renal dysfunction [14]. Constructively, use of tenofovir DF has also been reported for the reduction in mother to child transmission (MTCT) of Hepatitis B virus [15] and decrease in serum lipoprotein levels in chronic hepatitis B carriers [16]. Having substantial clinical applications, tenofovir DF has been extensively analyzed by UV spectrophotometric method [17], capillary electrophoresis [18], some HPLC methods [19-24], several LCMS/MS in biological fluids [25-29] and characterization of its degradation products by mass spectrometry [30]. Yet, to the best of our knowledge, there exists a lacuna in the implementation of QbD to analytical methods for the determination of tenofovir DF. The current paper serves to be the first to elucidate the systematic implementation of QbD to the development of a validated LC-MS method for the determination of tenofovir DF.

\section{MATERIALS AND METHODS}

Chemicals and reagents

Tenovofir DF active pharmaceutical ingredient (API) was received as a gift sample from Strides arcolabs limited (Bengaluru, India). The commercial formulation, Tenvir (300 mg tenofovir DF) by Cipla was procured from a local pharmacy. LC-MS grade acetonitrile and GR grade formic acid was procured from Thermo Fisher Scientific India 
Pvt. Ltd. (Waltham, Massachusetts, USA) and Merck Specialties Pvt. Ltd. (Darmstadt, Germany) respectively. Millipore Direct-Q® 3 UV water purification system, Merck millipore (Germany) was employed for HPLC type I water.

\section{Chromatographic conditions and apparatus}

Acquity UPLC $\AA$ (Waters, USA) using reverse-phase Acquity UPLC BEH C18 $(1.7 \mu \mathrm{m}, 1 \mathrm{~mm}$ X $50 \mathrm{~mm})$ column coupled in-line with Synapt G2 (Waters, USA) mass spectrometer was used for all chromatographic separations. ESI interface in positive mode directed column eluent to the mass spectrometer. The mobile phase pumped in gradient mode was composed of $0.1 \%$ formic acid as solvent A and acetonitrile (organic modifier) as solvent B. Organic modifier strength, flow rate, and injection volume were varied according to the experimental runs from the design of experiments (DoE). The total ion chromatograms (TIC) and mass spectrums were obtained and handled using MassLynx v.4.1

\section{Preparation of standard solutions}

$100 \mathrm{mg}$ of tenofovir DF was accurately weighed and dissolved in 100 $\mathrm{ml}$ acetonitrile, resulting in $1000 \mu \mathrm{g} / \mathrm{ml}$ standard stock solution. The standard stock solution was appropriately diluted to obtain $20 \mu \mathrm{g} / \mathrm{ml}$ to $150 \mu \mathrm{g} / \mathrm{ml}$ working standard solutions. The working standards were filtered through $0.2 \mu \mathrm{m}$ Phenex PTFE syringe filters from Phenomenex ${ }^{\circledR}$ before being injected for chromatographic analysis.

\section{Preparation of sample solutions}

Twenty tablets of tenofovir DF were weighed accurately and powdered. A weight equivalent to $100 \mathrm{mg}$ was weighed and dissolved in $100 \mathrm{ml}$ acetonitrile to obtain $1000 \mu \mathrm{g} / \mathrm{ml}$ solution. This solution was appropriately diluted to make concentration between $20 \mu \mathrm{g} / \mathrm{ml}$ to $100 \mu \mathrm{g} / \mathrm{ml}$ sample solutions. The sample solutions were filtered through $0.2 \mu \mathrm{m}$ Phenex PTFE syringe filters from Phenomenex $\AA$ before analysis.

\section{Method development through QbD approach}

\section{Expounding the ATP}

$\mathrm{QbD}$ approach to analytical methods commences with coherent identification of method objectives collectively termed as ATP. The principle behind defining ATP is to develop a method that meets the specified performance criteria [5]. As perceived from literature, predominantly, analytical methods are designed to be accurate, precise and robust ergo, the ATP for the present experiment was to develop a simple, accurate, precise, specific, and robust method.

\section{Defining the CQA}

The indispensable measurable parameters on which the ATP, quality and method performance recline are termed as the CQA. The CQA ensures that the method controls are productive and method performance is acceptable [31]. Since in chromatography, the quality of a peak echoes from good theoretical plates, and peak symmetry, while method performance indicated by retention time, the CQA identified for the present method development were retention time, theoretical plates, and peak tailing.

\section{Risk assessment studies}

Several experimental factors affect the CQA, altering the intended method performance, thus alarming-risk to the ATP. Systematic method development entails identification of such experimental factors and ranking them by the magnitude of their influence on CQA. Subsequently controlling these factors help achieve the intended method performance and mitigate the risk. Risk assessment studies aids to identify such factors and prioritize them accordingly. ICH Q9, quality risk management paradigm through its risk assessment necessitates risk identification, risk analysis and risk evaluation. Risk identification is based on experience, literature, historical data, trends, audits, cause-effect diagram, fishbone diagram, flow charts etc. Risk analysis estimates the risk associated with the identified factor using preliminary hazard analysis (PHA), failure mode effect analysis (FMEA), hazard analysis and critical control points (HACCP), Fault tree analysis (FTA), etc. which involves risk ranking to categorize the risks (e. g. low medium high).
Further, risk evaluation compares the estimated risk variables to the defined criterion qualitatively or quantitatively [32].

In the present paper, initial trials and literature reviews governed the identification of risk factors. Qualitative evaluation of the identified risk factors was achieved through simple risk ranking matrix. Based on the product of severity and probability the risk factors they were prioritized as low, medium and, high. For the quantitative evaluation of the high-risk factors, a screening was performed using DoE.

\section{Initial screening of high-risk factors using resolution $\mathrm{V}$ irregular fraction design}

DoE is a statistical tool where multivariate data is organized to fit empirical functions that elicit information about the factors' relation to the response and make cogent interpretations [1]. DoE presents a scope to control the number of experiments when large numbers of risk factors are involved with simultaneous randomization ensuring the effects of the variables will contribute to the repeatability variance of the response [33]. As a result, the factors that do not contribute to the variance can be expunged and remaining factors can be used for broader understanding [1]. Thus, DoE can be exercised for the screening of factors by thoroughly studying the main effect and possible interactions.

The authors have used resolution $\mathrm{V}$ irregular fraction design where 4-11 factors in two levels can be studied for their main effects and two-factor interactions with a reduced number of experiments thus carrying an advantage over regular full factorial and fractional factorial designs. All main effects are evaluated independently and the two-factor interactions are aliased with higher-order interactions. Thus, similar information about the main effects will be obtained from this design as would be found with a full $2^{4}$.

The risk factors identified for screening in their low and high levels were the organic modifier strength $10 \%$ (low)-30\% (high) for initial gradient condition, flow rate 0.2 (low) -0.4 (high) $\mathrm{ml} / \mathrm{min}$, injection volume 2 (low) -6 (high) $\mu \mathrm{l}$ and column temperature $30^{\circ} \mathrm{C}$ (low) $-40^{\circ} \mathrm{C}$ (high). This generated 12 experiments using Design Expert ${ }^{\circledR}$ v.11.0 software. The discerned CQA were the responses for evaluation. All experiments were performed using tenofovir DF working standard solution of $40 \mu \mathrm{g} / \mathrm{ml}$ concentration. The results were comprehended through Pareto charts to identify the statistically significant factors.

\section{Optimization using BBD}

Screened factors, organic modifier strength (10\%-30\%), flow rate $(0.2-0.4 \mathrm{ml} / \mathrm{min})$ and injection volume $(2 \mu \mathrm{l}-6 \mu \mathrm{l})$ were optimized through 17 experiments generated by BBD using Design Expert ${ }^{\circledR}$ v.11.0 software. BBD accomplishes a reduced number of experiments compared to its counter central composite design where each numeric factor can be set to three levels [33]. The criteria for numerical optimization were to establish factor values that generated maximum theoretical plates and minimum peak tailing within the range of the RT with ease. All experiments were performed using tenofovir DF working standard solution of $40 \mu \mathrm{g} / \mathrm{ml}$ concentration.

The results obtained were analyzed to determine significant factors by analysis of variance (ANOVA) $(\mathrm{p}<0.05)$, the goodness of fit $(\mathrm{R} 2)$ and factor coefficient values. The variations in CQA (responses) with changing factor levels were analyzed using the contour plots and 3D graphs. Numerical optimizing criteria was applied to draw factor values that best fit the criteria with ease and produce desirability close to one.

\section{Design space}

The multidimensional space that assures quality with changing factor combinations and interactions is termed as the design space [1]. It reflects the robustness of the optimized method. Graphical optimization was used to scout the design space at $95 \%$ tolerance with criteria being theoretical plates $>2000$ and peak tailing close to one with the range of RT.

\section{Control strategy}

The exhaustive knowledge reaped from such designed development studies results in instituting a control strategy. A control strategy is 
a set of orchestrated controls gleaned from method understanding that ensures incessant method performance and quality. It can be achieved either by automation of process parameters adjusted to achieve predefined results, nullifying end product testing or through adjusting the method variables within the design space to deliver acceptable results, reducing end product testing [2]. In either way, the aim of the control strategy is to continuously produce quality by controlling the variables.

\section{Analytical method validation}

Validation of the optimized analytical method was carried out following ICH Q2 (R1) guidelines [34], System suitability tests are performed considering that the types of equipment and analytical operations are an innate part of the experiment and must be subjected to evaluation. The test was performed on the UPLC-MS system by injecting six injections of $40 \mu \mathrm{g} / \mathrm{ml}$ working standard solution of tenofovir DF. The CQA were monitored and the relative standard deviation (RSD) calculated. The specificity of the method was established by injecting blank, working standard solution and sample solution. The analyte peak and presence of any interfering peak were monitored. The linearity was assessed injecting working standard solutions in triplicates $(n=3)$. The calibration curve was plotted to establish the linearity by the least square method using Microsoft Excel ${ }^{\circledR}$ with the concentration on the $x$-axis and peak area on the $y$ axis. The accuracy of the method was estimated by spiking the sample solution $(40 \mu \mathrm{g} / \mathrm{ml})$ with $20 \mu \mathrm{g} / \mathrm{ml}(80 \%), 40 \mu \mathrm{g} / \mathrm{ml}(100 \%)$ and 60 $\mu \mathrm{g} / \mathrm{ml}(120 \%)$ standard drug concentrations. All analysis was performed in triplicate $(n=3)$. The percent recovery was calculated and reported. The precision was estimated through repeatability and intermediate precision studies. The repeatability was established by consecutively injecting six $40 \mu \mathrm{g} / \mathrm{ml}$ working standard solution while, the for the intermediate precision, working standard 20, 40 and 60 $\mu \mathrm{g} / \mathrm{ml}$ were injected on three consecutive days, all in three replicates. The concentrations were calculated and the RSD reported. The Limit of Detection (LOD) and the Limit of Quantitation (LOQ) were established through the calibration curve data using LOD $=3.3^{*}$ standard deviation of the response/slope of the regression line and LOQ $=10^{*}$ standard deviation of the response/slope of the regression line.

\section{Analysis of formulation}

The optimized method was used for the analysis of the marketed formulation of tenofovir DF, Tenvir (tenofovir disoproxil fumarate$300 \mathrm{mg}$ ). Sample solution of $40 \mu \mathrm{g} / \mathrm{ml}$ was prepared, filtered and injected for the analysis and calculation of $\%$ assay from the eluted analyte peak. The $\%$ assay was calculated from equation 1 [35].

$$
\frac{(\mathrm{AT} * \mathrm{WS} * \mathrm{DT} * \mathrm{P} * \text { Average weight } * 100)}{(\mathrm{AS} * \mathrm{DS} * \mathrm{WT} * 100 * \text { Label claim }} \text { Equation } 1
$$

Where;

$\mathrm{A}_{\mathrm{T}}=$ area of the peak from sample solution (test)

$A_{S}=$ area of the peak from standard drug

$\mathrm{W}_{\mathrm{S}}=$ weight of the standard drug taken

$\mathrm{W}_{\mathrm{T}}=$ weight of the tablet taken

$\mathrm{D}_{\mathrm{s}}=$ dilution factor of standard solution

$\mathrm{D}_{\mathrm{T}}=$ dilution factor of sample solution

$\mathrm{P}=$ Percentage purity of the standard drug

\section{Forced degradation studies}

Acid, base and neutral (thermal-wet) hydrolysis was carried out by dissolving $10 \mathrm{mg}$ of tenofovir DF (API) in $10 \mathrm{ml}$ of $0.1 \mathrm{~N} \mathrm{HCl}, 0.1 \mathrm{~N}$ $\mathrm{NaOH}$ and millipore water respectively in separate round bottom flasks (RBFs). The RBFs were refluxed for $60 \mathrm{~min}$ at $80^{\circ} \mathrm{C}$. In the end, $1 \mathrm{ml}$ solution each from the RBFs were pipetted, cooled to room temperature and neutralized. The final volumes were made up to 10 $\mathrm{ml}$ using millipore water. These solutions after filtration were injected and analyzed $[30,36]$.

Oxidative hydrolysis was carried out using 3\% and 30\% hydrogen peroxide solution. $10 \mathrm{mg}$ of tenofovir DF (API) each was dissolved in $3 \%$ and $30 \%$ hydrogen peroxide in separate RBFs and refluxed at 80 ${ }^{\circ} \mathrm{C}$ for $60 \mathrm{~min}$. In the end, $1 \mathrm{ml}$ solution from each was pipetted, cooled to room temperature and final volume made up to $10 \mathrm{ml}$ each using millipore water. These solutions after filtration were injected into UPLC-MS system [30, 36].

Photolytic degradation was carried out by direct exposure of tenofovir DF working standard solution to UV light $(320 \mathrm{~nm})$ for a day. Later, the solution was filtered and injected for analysis. All the stressed samples were analyzed for the analyte peak [18].

\section{RESULTS AND DISCUSSION}

\section{Risk assessment studies}

Identifying the CQA necessitate the study of various factors affecting them. Factors identified through inceptive trials and their risk evaluation (fig 1 ) by the product of their probability of occurrence and severity, evinced organic modifier strength (\%), flow rate, injection volume and column temperature as high-risk factors among the myriad factors as listed in fig. 1. These high-risk factors were considered for evaluating their significance through DoE.

\begin{tabular}{|c|c|c|c|c|c|c|c|c|c|c|}
\hline $\begin{array}{l}\text { Identified } \\
\text { risk }\end{array}$ & $\begin{array}{l}\text { Primarily } \\
\text { affects }\end{array}$ & \multicolumn{8}{|c|}{ Risk Eraluation } & \multirow{2}{*}{$\begin{array}{c}\begin{array}{c}\text { Risk } \\
\text { Scoring } \\
(\mathrm{P} \star \mathrm{S})\end{array} \\
1\end{array}$} \\
\hline solubility & Recovery & \multirow{3}{*}{\multicolumn{3}{|c|}{ Risk ranking matrix }} & \multicolumn{5}{|c|}{ Sererity (S) } & \\
\hline $\begin{array}{l}\text { Organic } \\
\text { Modifier }\end{array}$ & Retention time & & & & Negligible & Minor & Moderate & Major & Serere & 9 \\
\hline $\begin{array}{c}\text { Organic } \\
\text { Modifier } \\
\text { (initial \%) }\end{array}$ & Retention time & & & & 1 & 2 & 3 & 4 & 5 & 16 \\
\hline $\begin{array}{l}\text { Injection } \\
\text { volume }\end{array}$ & Peak quality & \multirow{5}{*}{$\begin{array}{l}\text { Probability } \\
\text { (P) }\end{array}$} & seldom & 1 & 1 & 2 & 3 & 4 & 5 & 16 \\
\hline $\begin{array}{l}\text { Separation } \\
\text { mode }\end{array}$ & Peak elution & & $\begin{array}{l}\text { unlikely } \\
\text { to occur }\end{array}$ & 2 & 2 & 4 & 6 & 8 & 10 & 4 \\
\hline Flow Type & $\begin{array}{l}\text { Retention time, } \\
\text { Peak elution }\end{array}$ & & $\begin{array}{l}\text { Could } \\
\text { occur }\end{array}$ & 3 & 3 & 6 & 9 & 12 & 15 & 9 \\
\hline Flow Rate & $\begin{array}{l}\text { Retention time, } \\
\text { Peak quality }\end{array}$ & & $\begin{array}{l}\text { likely to } \\
\text { occur }\end{array}$ & 4 & 4 & 8 & 12 & 16 & 20 & 16 \\
\hline $\begin{array}{l}\text { Column } \\
\text { temperature }\end{array}$ & Peak quality & & Certain & 5 & 5 & 10 & 15 & 20 & 25 & 16 \\
\hline Column type & $\begin{array}{l}\text { Retention time, } \\
\text { Peak quality }\end{array}$ & \multicolumn{8}{|c|}{ High risk factors are considered for further analysis } & 4 \\
\hline
\end{tabular}

Fig. 1: Risk evaluation matrix 
Initial screening of risk variables using resolution $\mathrm{V}$ irregular fraction design

The results of initial screening by resolution $\mathrm{V}$ irregular factorial design were analyzed using the Pareto charts. The Pareto chart is an indicator of the t-test, where the calculated t-values (effect) are compared to the table t-values. Factors with frequencies crossing the table t-value (horizontal black line across) were considered significant (fig. 2). Statistically, if calculated t-values are greater than table t-values, the null hypothesis is rejected, inferring the changes in response were due to change in factor values, concluding the factor significance. Following which, organic modifier strength, flow rate, and injection volume were found to be significant and thus selected for optimization. As the effect of column temperature was not significant, it was set at an intermediate level of $35^{\circ} \mathrm{C}$ for further experiments.
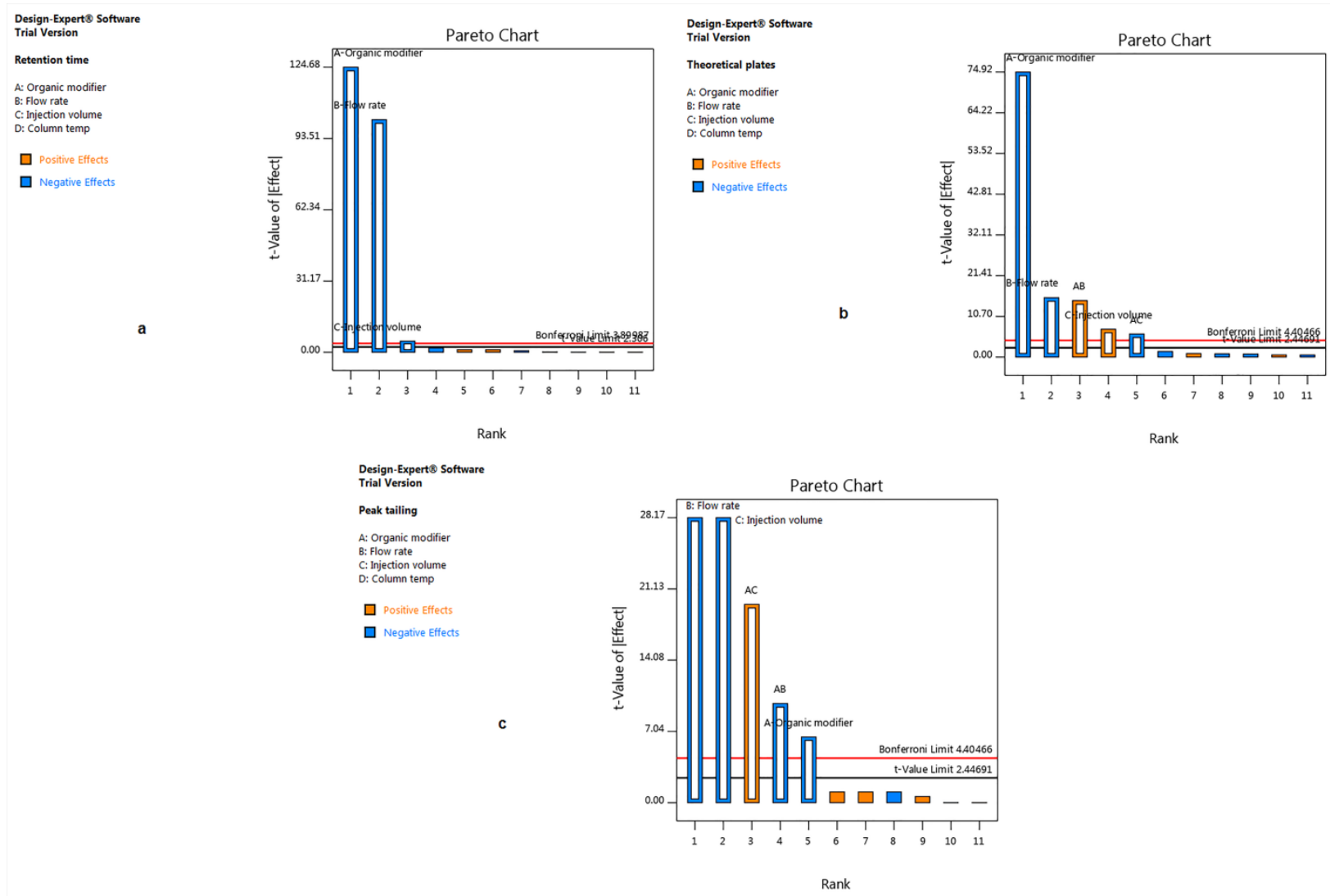

Fig. 2: Pareto chart for factor significance to (a) Retention time, (b) Theoretical plates and (c) Peak tailing

Table 1: Lists of optimizing experiments from BBD and their generated responses

\begin{tabular}{|c|c|c|c|c|c|c|c|}
\hline \multicolumn{4}{|c|}{ Factors } & Units & Low & Mid & High \\
\hline \multicolumn{4}{|c|}{ Organic modifier } & $\%$ & 10 & 20 & 30 \\
\hline \multicolumn{4}{|c|}{ Flow rate } & $\mathrm{ml} / \mathrm{min}$ & 0.2 & 0.4 & 0.6 \\
\hline \multicolumn{4}{|c|}{ Injection volume } & $\mu \mathrm{l}$ & 2 & 4 & 6 \\
\hline \multicolumn{2}{|c|}{ Experiment } & \multicolumn{3}{|l|}{ Factors (X) } & \multicolumn{3}{|l|}{ Responses (Y) } \\
\hline Std. & Run & A: organic modifier & B: Flow rate & C: Injection volume & Retention time (min) & Theoretical plates & Peak tailing \\
\hline 6 & 1 & 30 & 0.4 & 2 & 1.18 & 478.759 & 1.08 \\
\hline 10 & 2 & 20 & 0.6 & 2 & 1.95 & 989.814 & 1.25 \\
\hline 5 & 3 & 10 & 0.4 & 2 & 3.41 & 2907.04 & 1.18 \\
\hline 9 & 4 & 20 & 0.2 & 2 & 3.72 & 1498.9 & 1.35 \\
\hline 16 & 5 & 20 & 0.4 & 4 & 2.49 & 2490.28 & 1.03 \\
\hline 17 & 6 & 20 & 0.4 & 4 & 2.49 & 2893.38 & 1.03 \\
\hline 7 & 7 & 10 & 0.4 & 6 & 3.40 & 3129.5 & 0.99 \\
\hline 3 & 8 & 10 & 0.6 & 4 & 2.90 & 2116.89 & 1.23 \\
\hline 1 & 9 & 10 & 0.2 & 4 & 4.51 & 2789.92 & 1.33 \\
\hline 13 & 10 & 20 & 0.4 & 4 & 2.49 & 2490.28 & 1.03 \\
\hline 12 & 11 & 20 & 0.6 & 6 & 1.93 & 1466.17 & 1.14 \\
\hline 2 & 12 & 30 & 0.2 & 4 & 2.19 & 300.814 & 1.35 \\
\hline 14 & 13 & 20 & 0.4 & 4 & 2.49 & 2490.28 & 1.03 \\
\hline 8 & 14 & 30 & 0.4 & 6 & 1.16 & 620.867 & 1.06 \\
\hline 15 & 15 & 20 & 0.4 & 4 & 2.49 & 2490.28 & 1.03 \\
\hline 11 & 16 & 20 & 0.2 & 6 & 3.69 & 1926.71 & 1.25 \\
\hline 4 & 17 & 30 & 0.6 & 4 & 0.82 & 199.124 & 1.17 \\
\hline
\end{tabular}




\section{Optimization using BBD}

The responses to changing factors through the 17 experiments produced from BBD are shown in table 1. The results were analyzed using ANOVA, fit statistics and coefficient values for the main effects and interactions as shown in table 2, table 3 and table 4 respectively. The large F-values and models p-value, $<0.05$ advocated factor significance. A p-value $<0.05$ rejects the nul hypothesis, here, establishing the significance of selected factors. The goodness of fit $\left(\mathrm{R}^{2}\right)$ values being close to one, show good proximity of the data to the fitted regression line. The adjusted $\mathrm{R}^{2}$ and predicted $\mathrm{R}^{2}$ differed by less than 0.2 indicating negligible block effect. Observing the coefficient values inferred that the experimental model followed second-order quadratic polynomial equation (Equation 2).
$\mathrm{Y}=\beta 0+\beta 1 * \mathrm{X} 1+\beta 2 * \mathrm{X} 2+\beta 3 * \mathrm{X} 3+\beta 4 * \mathrm{X} 1 * \mathrm{X} 2+\beta 5 * \mathrm{X} 2 * \mathrm{X} 3+$ $\beta 6 * X 1 * X 3+\beta 7 * X 1 * X 1+\beta 8 * X 2 * X 2+\beta 9 * X * X 3$-Equation 2

Where

$\mathrm{Y}$ is the response value

$\beta 0$ is the intercept

$\beta 1-\beta 9$ is the coefficient of each term

$\mathrm{X}=$ desired factor values

As the model was fit to predict variations in response with varying factor values significantly, it was used to predict optimized values and explore the design space.

Table 2: ANOVA results for the optimizing experiments

\begin{tabular}{|c|c|c|c|c|c|c|}
\hline \multirow[b]{2}{*}{ Source } & \multicolumn{2}{|c|}{ Retention time } & \multicolumn{2}{|c|}{ Theoretical plates } & \multicolumn{2}{|c|}{ Peak tailing } \\
\hline & F-value & p-value & F-value & p-value & F-value & p-value \\
\hline Model & 319.5 & $<0.0001$ & 59.44 & $<0.0001$ & 311.3 & $<0.0001$ \\
\hline A-Organic modifier & 1794.57 & $<0.0001$ & 370.4 & $<0.0001$ & 6.86 & 0.0345 \\
\hline B-Flow rate & 968.85 & $<0.0001$ & 12.91 & 0.0088 & 336.14 & $<0.0001$ \\
\hline C-Injection volume & 0.1852 & 0.6799 & 6.83 & 0.0047 & 246.96 & $<0.0001$ \\
\hline $\mathrm{AB}$ & 2.63 & 0.1487 & 2.77 & 0.14 & 17.92 & 0.0039 \\
\hline $\mathrm{AC}$ & 0.0183 & 0.8962 & 0.0548 & 0.8216 & 80.92 & $<0.0001$ \\
\hline $\mathrm{BC}$ & 0.0046 & 0.948 & 0.02 & 0.8915 & 0.28 & 0.6131 \\
\hline$A^{2}$ & 33.56 & 0.0007 & 29.3 & 0.001 & 57.77 & 0.0001 \\
\hline $\mathrm{B}^{2}$ & 80.71 & $<0.0001$ & 83.94 & $<0.0001$ & 1981.81 & $<0.0001$ \\
\hline $\mathrm{C}^{2}$ & 0.059 & 0.8151 & 15.95 & 0.0052 & 7.37 & 0.03 \\
\hline
\end{tabular}

Table 3: Fit-statistics of the responses

\begin{tabular}{llll}
\hline Fit statistics & Retention time & Theoretical plates & Peak tailing \\
\hline $\mathrm{R}^{2}$ & 0.9976 & 0.9871 & 0.9975 \\
Predicted $\mathrm{R}^{2}$ & 0.9611 & 0.9109 & 0.9601 \\
Adjusted $\mathrm{R}^{2}$ & 0.9944 & 0.9705 & 0.9943 \\
\hline
\end{tabular}

Table 4: Co-efficient values of the factors

\begin{tabular}{llll}
\hline & Retention time & Theoretical plates & Peak tailing \\
\hline Factor & Coefficient & Coefficient & Coefficient \\
\hline Intercept & 2.46 & 2570.90 & 1.030 \\
A-Organic modifier & -1.11 & -1167.97 & -0.009 \\
B-Flow rate & -0.8138 & -218.04 & -0.061 \\
C-Injection volume & -0.0113 & 158.59 & -0.053 \\
AB & 0.06 & 142.83 & -0.020 \\
AC & -0.005 & -20.09 & 0.043 \\
BC & 0.0025 & 12.14 & -0.003 \\
$A^{2}$ & -0.1938 & -452.79 & 0.035 \\
$B^{2}$ & 0.3387 & -766.43 & 0.205 \\
$C^{2}$ & 0.0238 & -334.08 & 0.013 \\
\hline
\end{tabular}

The fashion in which varying factor values affected the CQA were perceived from the 3D surface plots of the responses. Fig. 3 corresponding to 3D surface plots of RT, shows an increase in RT towards low organic modifier strength and low flow rate while injection volume incurred a negligible effect. The behavioral pattern of factors on the theoretical plate was demonstrated from fig. 4, indicating a maximum at a medium flow rate, low organic modifier strength, and high injection volume. The effect of factors on peak tailing deduced from fig. 5 suggested low peak tailing at a medium flow rate and low organic modifier strength with high injection volume.

The above understanding was extrapolated to numerical optimization for reckoning variable values that generate inimitable quality and method performance with ease to achieve the ATP. The criteria for numerical optimization being maximum theoretical plates and minimum peak tailing within the range of RT cropped $10 \%$ organic modifier strength, $0.4 \mathrm{ml} / \mathrm{min}$ flow rate, and $6 \mu \mathrm{l}$ injection volume as the optimized method conditions with desirability near one (fig. 6). The gradient elution condition was then set to initial: $90.0(\% \mathrm{~A}) 10.0(\% \mathrm{~B}), 4 \mathrm{~min}: 60.0(\% \mathrm{~A}) 40.0(\% \mathrm{~B})$, 5 min: $60.0(\% \mathrm{~A}) 40.0(\% \mathrm{~B}), 7 \mathrm{~min}: 90.0(\% \mathrm{~A}) 10.0(\% \mathrm{~B})$ and at 8 min to $90.0(\% \mathrm{~A}) 10.0(\% \mathrm{~B})$, all at $0.4 \mathrm{ml} / \mathrm{min}$ flow rate. Adopting the optimized method condition tenofovir DF eluted unimpeded at $3.40 \mathrm{~min}$ indicated by the $\mathrm{m} / \mathrm{z}$ value 520 (parent ion peak) as shown in fig. 7.

\section{Design space}

The earmark of a sustainable analytical method is the design space emblematic of robustness. Graphical optimization as shown in fig. 8 divulged the design space as yellow highlighted areas representing acceptable responses matching the set criteria with the change in factor values, thus, design space affirms the robustness of the optimized method conditions within the defined limits and increases the reliability of the method. 

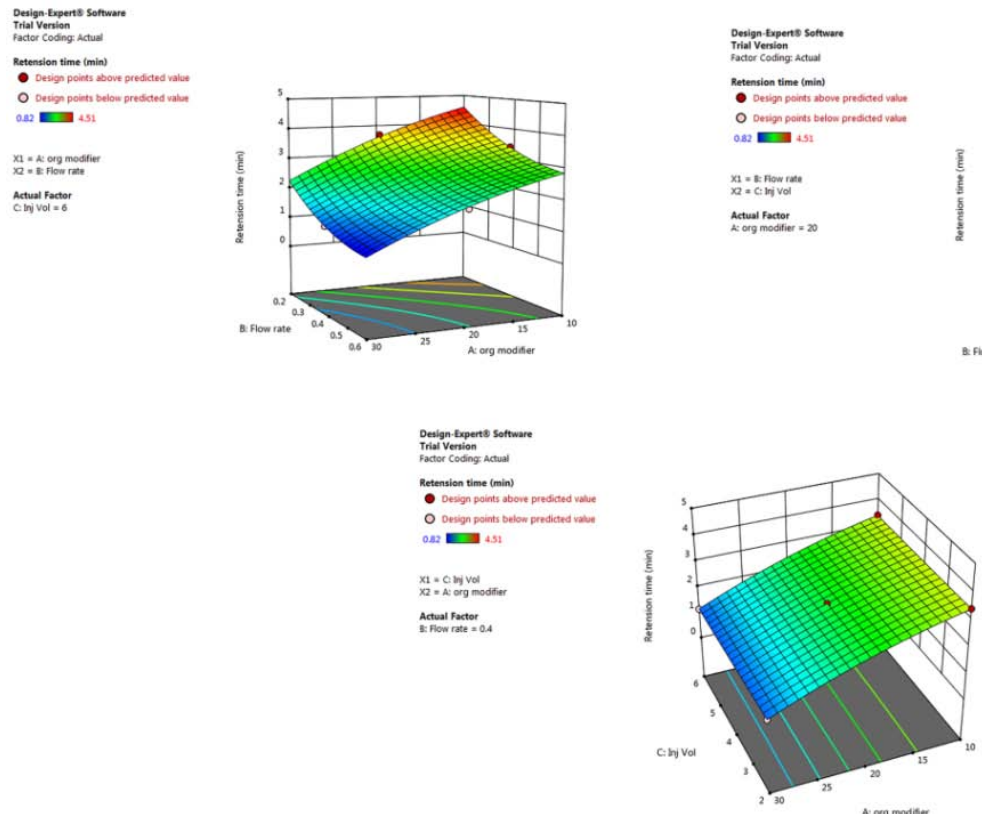

Fig. 3: 3D surface plot for RT

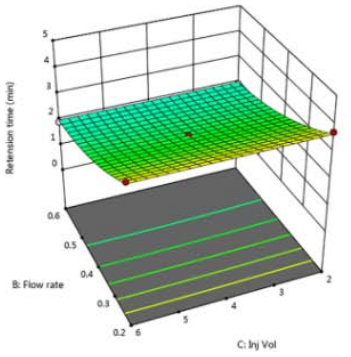

cinvol
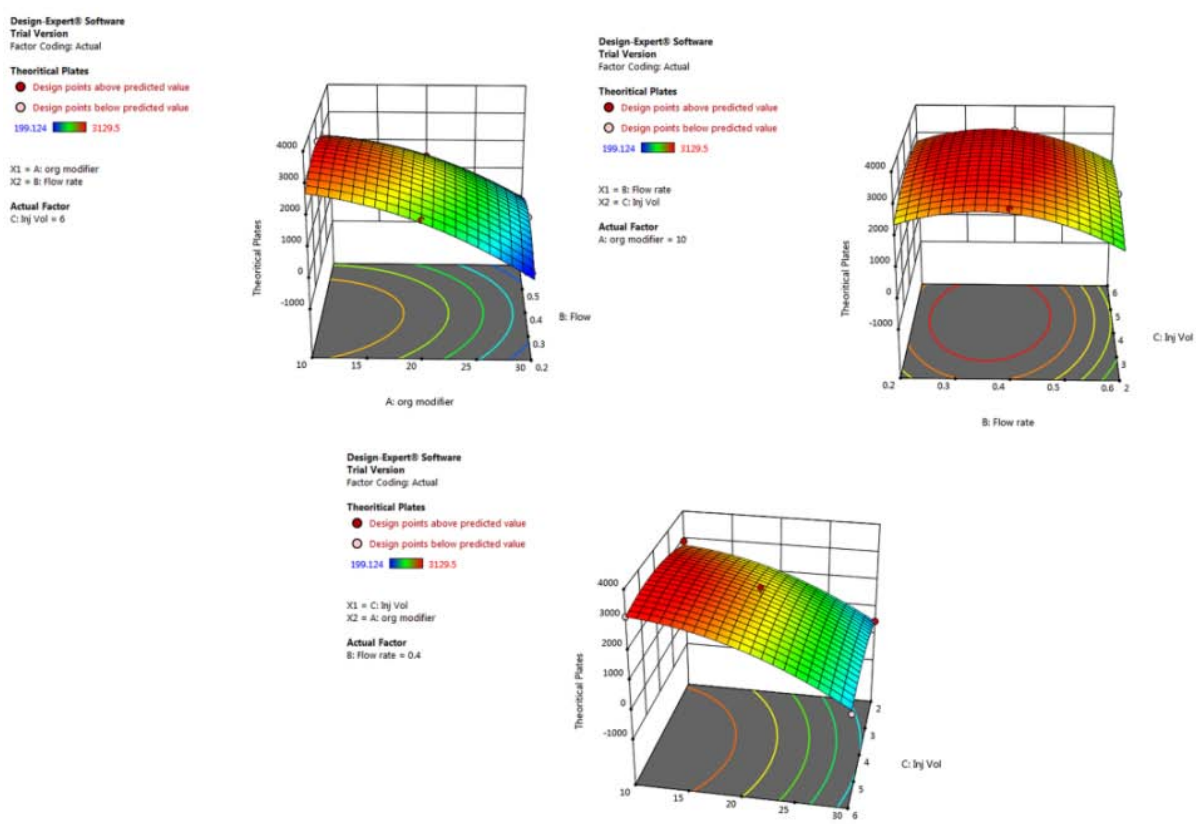

Fig. 4: 3D surface plot for theoretical plate

\section{Control strategy}

In order to control the analytical method development such that it generates incessant method performance and quality, the factors influencing the CQAs were monitored and were set to optimized conditions that can be stretched maximum within the design space.

\section{Analytical method validation}

The method was found to be specific as the analyte eluted without any interference following the injection from the blank, the working standard solution and the sample solution (fig. 9). The system was suitable for the analysis as indicated by the system suitability results shown in table 5 [37]. The analytical method proves to be linear in the range of $20-100 \mu \mathrm{g} / \mathrm{ml}$ as calibration plot statistically justifies the linearity with $\mathrm{R}^{2}=0.9998$, inferring the closeness of the data to the fitted regression line, as shown in fig. 10. The calibration curve followed the regression equation $y=227.25 x+0.4762$. The method showed acceptable accuracy with recovery between 98.71 to 101.17 $\%$ (table 6 ). The compendium limits for the recovery was between $97-102 \%$ tenofovir DF [38]. The method was observed to be precise as RSD was $<2 \%$, listed in table 7 . The calculated LOD and LOQ of Tenofovir DF were $5.50 \mu \mathrm{g} / \mathrm{ml}$ and $16.68 \mu \mathrm{g} / \mathrm{ml}$ respectively.

\section{Analysis of formulation}

The \% assay for the analysis of Tenvir tablets containing $300 \mathrm{mg}$ tenofovir DF was calculated to be $99.96 \%$ and was observed to be satisfactory as the compendia limit was between 90 to $110 \%$ for tenofovir disoproxil tablets [38]. 

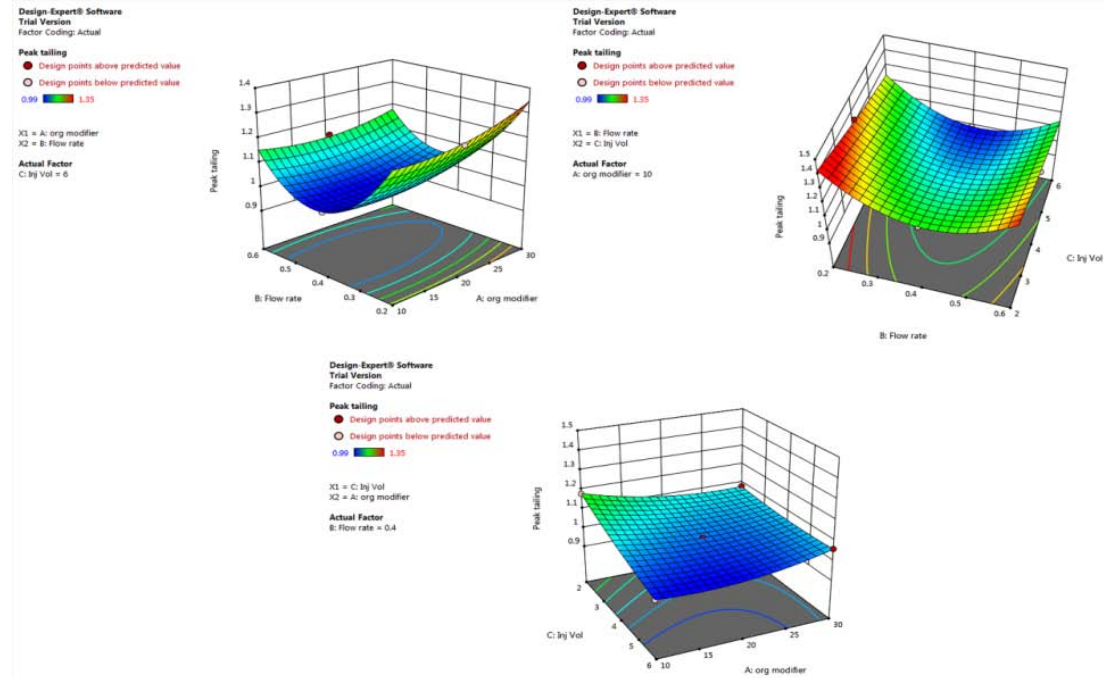

Fig. 5: 3D surface plot for peak tailing
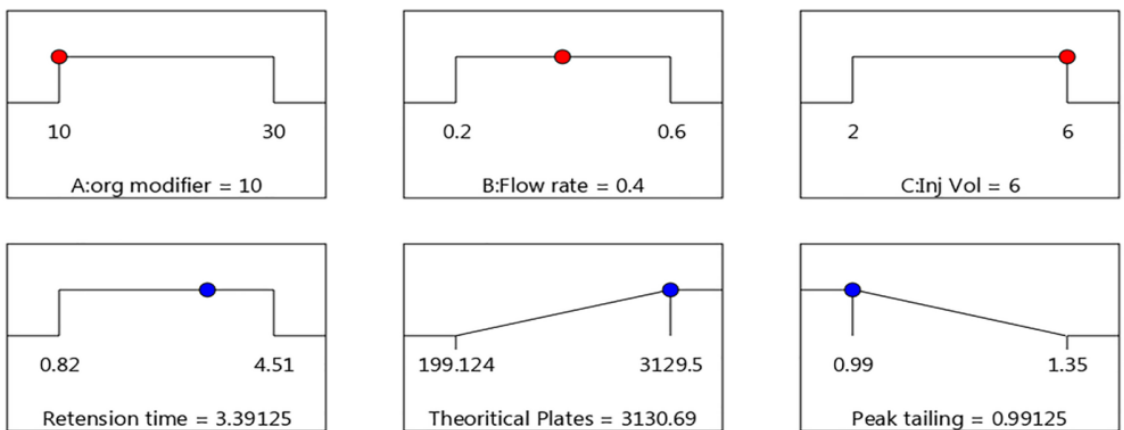

Desirability $=0.998$

Fig. 6: Numerical optimization for tenofovir DF

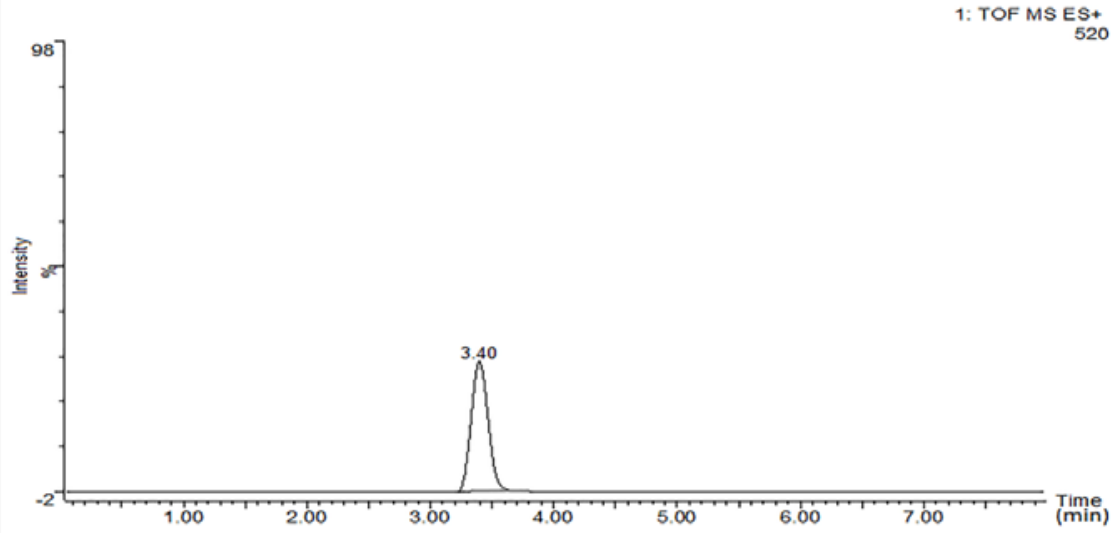

a

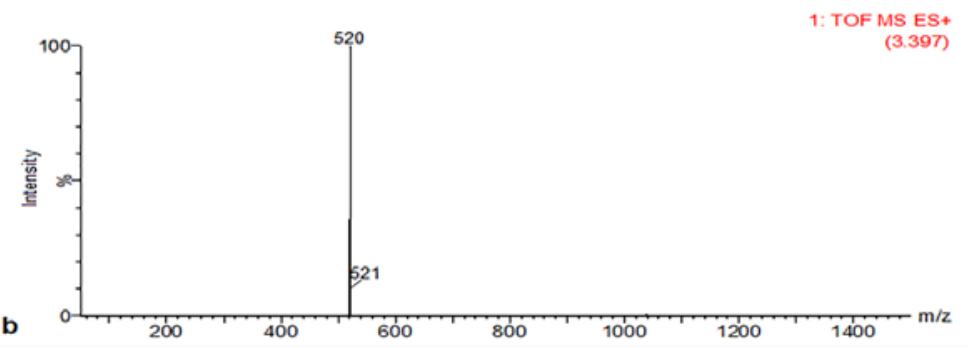

Fig. 7: (a) Optimized peak of tenofovir DF and its (b) parent ion peak 

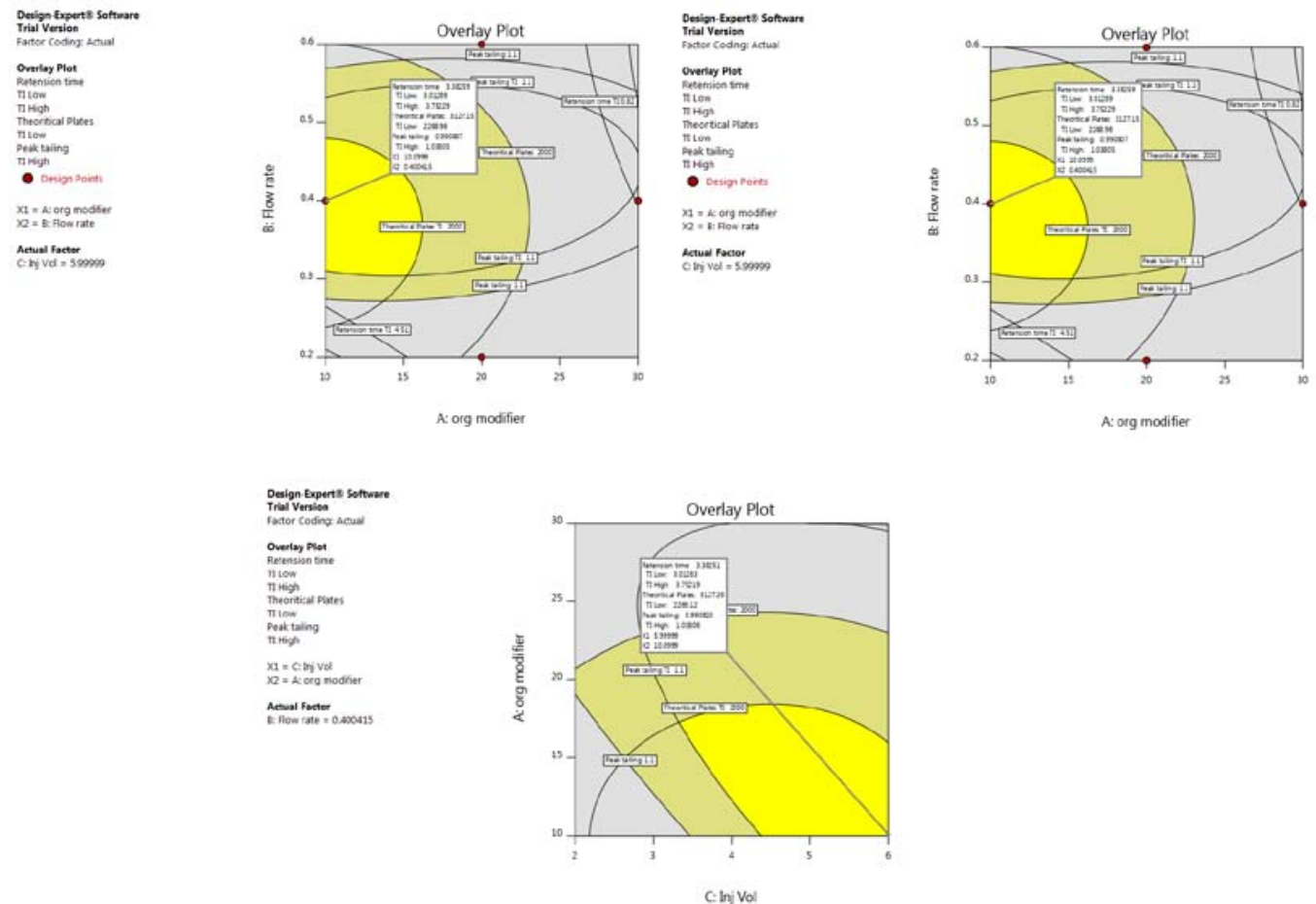

Fig. 8: Design space for tenofovir DF
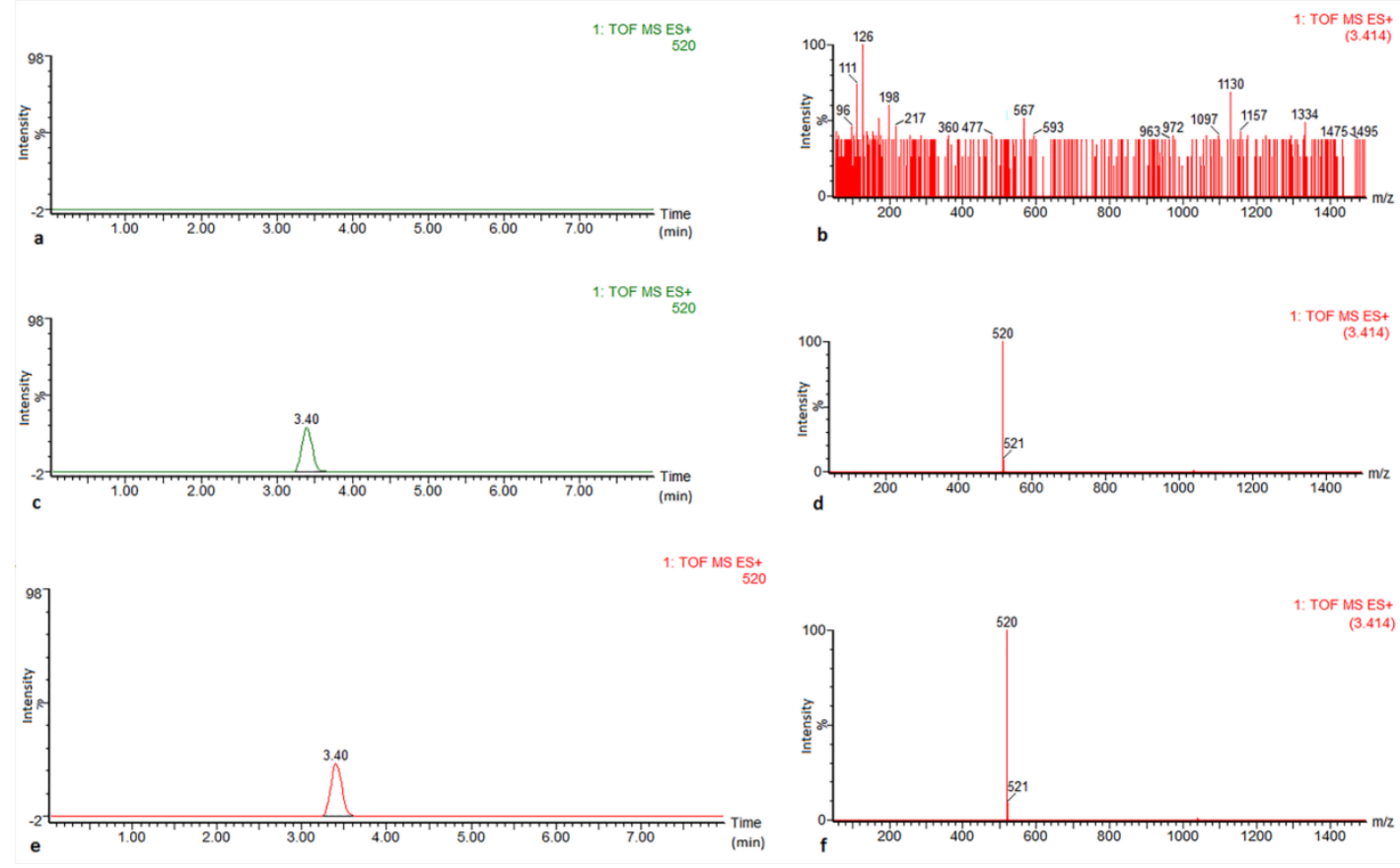

Fig. 9: a, c and e: Typical total ion chromatogram of blank, working standard and sample solution respectively. (b), (d) and (f): Mass line spectrum of blank, working standard and sample solution respectively of tenofovir DF

Table 5: System suitability for tenofovir DF

\begin{tabular}{|c|c|c|c|c|}
\hline S. No & $\begin{array}{l}\text { Concentration } \\
(\mu \mathrm{g} / \mathrm{ml})\end{array}$ & $\begin{array}{l}\text { RT }(\min )(\text { mean } \pm \text { SD) }(n= \\
6)\end{array}$ & $\begin{array}{l}\text { Theoretical plates } \\
(\text { mean } \pm S D)(n=6)\end{array}$ & $\begin{array}{l}\text { Peak tailing (mean } \pm S D)(n= \\
6)\end{array}$ \\
\hline 1 & 40.00 & $3.40 \pm 0.00$ & $3220.55 \pm 14.10$ & $0.90 \pm 0.56$ \\
\hline RSD (\%) & & 0.00 & 0.44 & 0.56 \\
\hline Acceptance limit & - & - & NLT 2000 & NMT 2 \\
\hline
\end{tabular}

$\mathrm{n}=$ number of experiments, NLT $=$ Not Less Than, NMT $=$ Not More Than, $\mathrm{RT}=$ Retention Time, RSD $=$ Relative Standard Deviation, $\mathrm{SD}=\mathrm{Standard}$ Deviation 


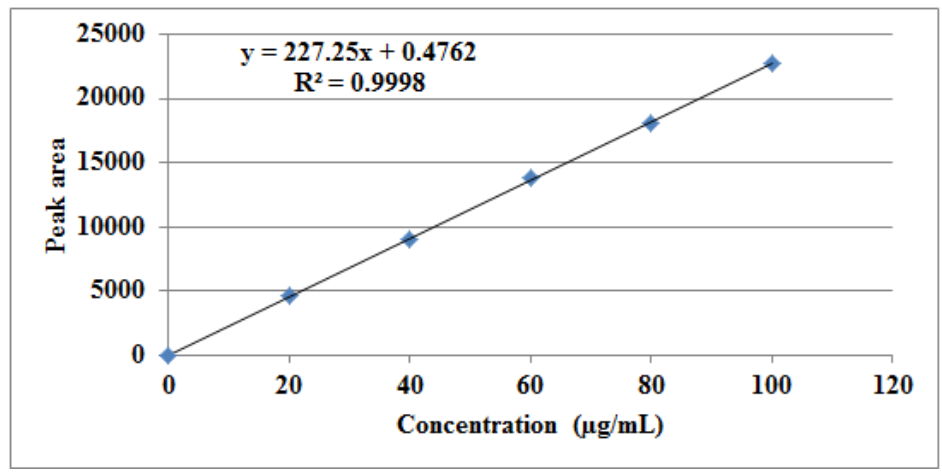

Fig. 10: Calibration curve for linearity of tenofovir DF

Table 6: Results of accuracy study of tenofovir DF

\begin{tabular}{|c|c|c|c|c|}
\hline$\%$ & Amount spiked $(\mu \mathrm{g} / \mathrm{ml})$ & Amount found $(\mu \mathrm{g} / \mathrm{ml})$ & \% Recovery (mean \pm SD) & RSD $(n=3)$ \\
\hline \multirow[t]{3}{*}{50.00} & 20.00 & 20.18 & $101.23 \pm 0.67$ & 0.66 \\
\hline & 20.00 & 20.16 & & \\
\hline & 20.00 & 20.40 & & \\
\hline \multirow[t]{3}{*}{100.00} & 40.00 & 40.14 & $100.20 \pm 0.42$ & 1.05 \\
\hline & 40.00 & 39.89 & & \\
\hline & 40.00 & 40.21 & & \\
\hline \multirow[t]{3}{*}{150.00} & 60.00 & 60.31 & $101.04 \pm 0.57$ & 0.94 \\
\hline & 60.00 & 60.57 & & \\
\hline & 60.00 & 60.99 & & \\
\hline
\end{tabular}

$\mathrm{n}=$ number of experiments, RSD = Relative Standard Deviation, $\mathrm{SD}=$ Standard Deviation

Table 7: Results of precision studies of tenofovir DF

\begin{tabular}{lcc}
\hline Concentration $(\mu \mathrm{g} / \mathrm{ml})$ & Concentration found $(\boldsymbol{\mu g} / \mathbf{m l})(\mathbf{m e a n} \pm$ SD) & RSD (\%) \\
\hline Repeatability $(\mathrm{n}=6)$ & $40.20 \pm 0.11$ & 0.26 \\
40 & & \\
Intermediate precision $(\mathrm{n}=3)$ & $20.25 \pm 0.13$ & 0.66 \\
20 & $40.18 \pm 0.18$ & 0.44 \\
40 & $60.62 \pm 0.34$ & 0.57 \\
60
\end{tabular}

$\mathrm{n}=$ number of experiments, $\mathrm{SD}=$ Standard Deviation, $\mathrm{RSD}=$ Relative Standard Deviation
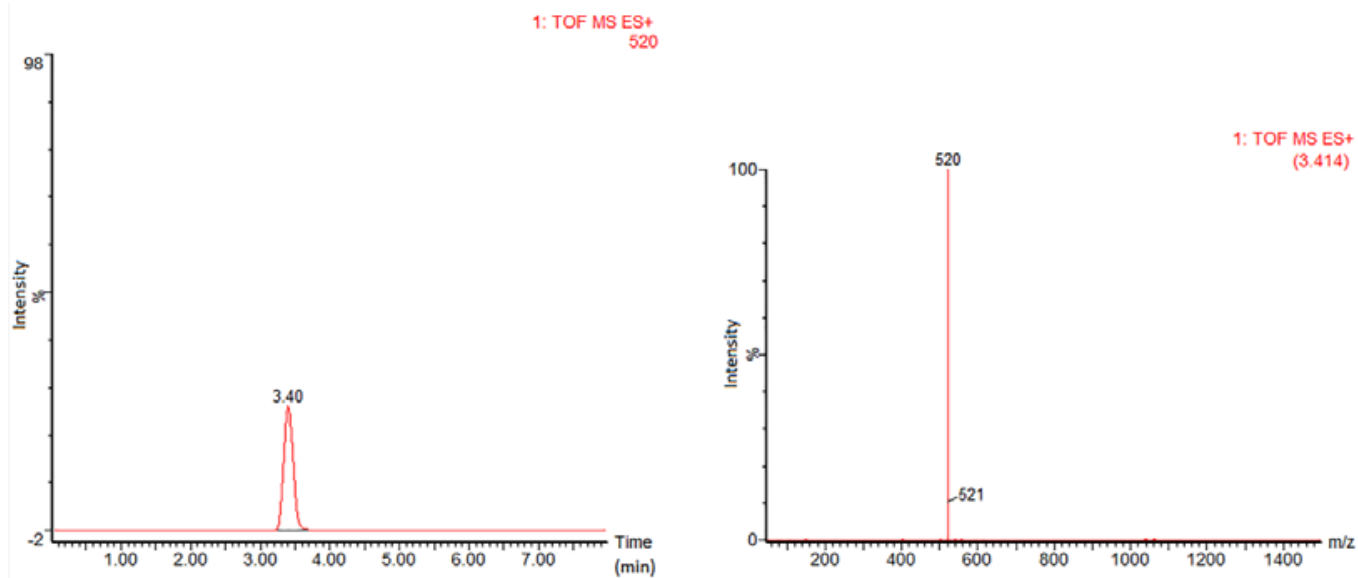

Fig. 11: A typical total ion chromatogram (left) and mass line spectrum (right) of the analyzed formulation of tenofovir DF

\section{Forced degradation studies}

Tenofovir DF, a prodrug completely degraded in acid and basic conditions to tenofovir. Indicated by the $m / z$ value of 288 [fig.12 (a), (b)] the degradation to tenofovir was affirmed as the molecular weight of tenofovir is $287.216 \mathrm{~g} / \mathrm{mol}$ [39]. Tenofovir DF shows slight degradation with the formation of an intermediate in thermal conditions as suggested by the mass transition, $m / z$ 520-404, shown in fig. 12 (c). Tenofovir DF was found to be stable within the experimental oxidative condition of $3 \% \mathrm{H}_{2} \mathrm{O}_{2}$ and $30 \% \mathrm{H}_{2} \mathrm{O}_{2}$ also in photolytic conditions as shown in fig. 13.

The comprehended structural changes corresponding to the changes in $m / z$ ratio were demonstrated using ChemDraw $®$ V.15, shown in fig.14. The above understanding aligns with Kurmi's work on the characterization of tenofovir DF degradation product [30]. 

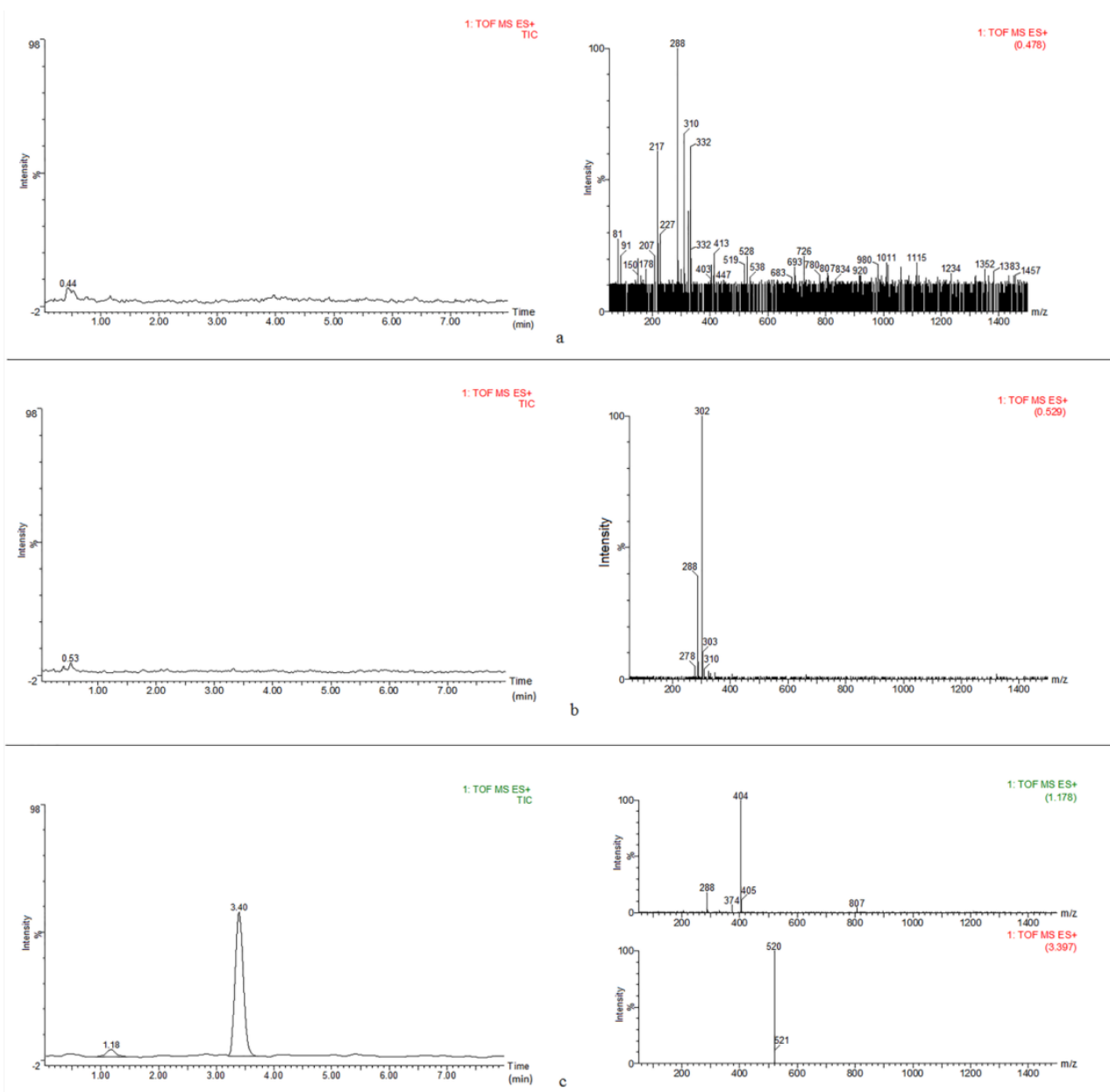

Fig. 12: Total ion chromatograms (left) and line spectrum (right) of (a) acid degradation, (b) basic degradation and (c) thermal degradation of tenofovir DF
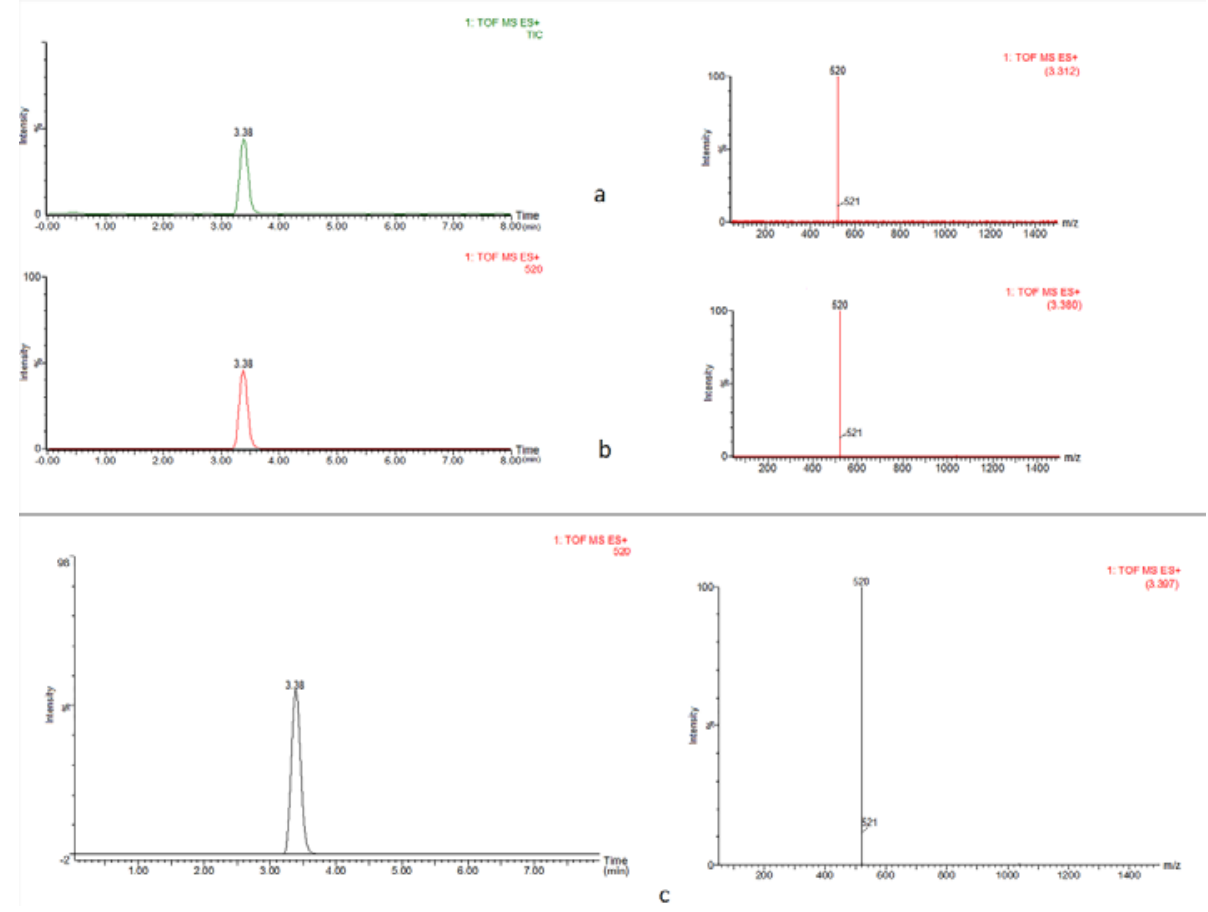

Fig. 13: Total ion chromatogram (left) and line spectrum of (a) $3 \% \mathrm{H} 202$ degradation, (b) $30 \% \mathrm{H} 202$ degradation and (c) photolytic degradation of tenofovir DF 


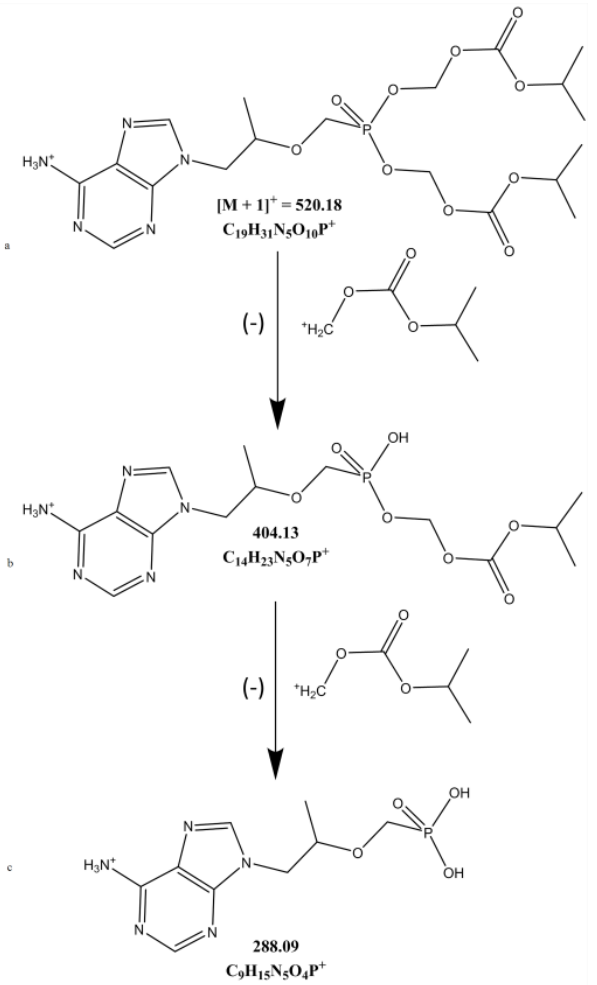

Fig. 14: Estimated path of degradation tenofovir DF

\section{DISCUSSION}

With stringent regulatory interventions in the pharmaceutical market, it is not merely enough to develop a method for the determination of an analyte. It has now become mandatory to impart quality within the method development process rather than to the finished product. Several research papers reviewed [17-24] during the present study failed to demonstrate the rationality behind the method conditions and optimization technique. The current $\mathrm{QbD}$ approach is novel for the determination of tenofovir $\mathrm{DF}$. It not only statistically rationalizes the optimization process but also demonstrates the possible changes to CQA with changes in method condition. Design space highlights the range of the factors beyond which the desired elution of the analyte can be affected. To the best of our knowledge, no other papers for the determination of tenofovir DF have demonstrated the design space. Further, the use of simple mobile phase to achieve low retention time differentiates the present work from several others reported earlier [19-24, 40].

\section{CONCLUSION}

QbD paradigm has been successfully employed to the development of validated stability-indicating LC-MS method for the estimation of tenofovir DF. The approach coherently defined the ATP following which the CQAs were identified. Myriad factors affecting the CQAs were judiciously scouted through risk assessment studies. Further high-risk factors were empirically screened through resolution $V$ irregular fraction design. The correlation between the screened high-risk factors and CQA were learned and their values were statistically optimized to meet the method criteria via BBD. The optimized conditions and the design space that embodied robustness upheld the desired method performance and quality. The optimized method was validated pursuant to ICH guidelines. Unimpeded elution of the analyte with presumed mass transitions affirmed the specificity of the method. The conventional method development received an avant-garde design through this paper and is assumed the first for the estimation of tenofovir DF. The present work expounds the concept of QbD, showing methodical planning and orderly execution can reduce risk, experimental burden, and errors ergo, application to various research areas is being foresighted.

\section{ACKNOWLEDGMENT}

The authors sincerely acknowledge JSS Academy of Higher Education \& Research also the University of Mysore, Institution of excellence (IOE) for their laboratory assistance.

\section{AUTHORS CONTRIBUTIONS}

All the author have contributed equally

\section{CONFLICT OF INTERESTS}

The authors have no conflict of interest

\section{REFERENCES}

1. Tabora JE, Domagalski N. Multivariate analysis and statistics in pharmaceutical process research and development. Annu Rev Chem Biomol Eng 2017;8:403-26.

2. Yu LX, Amidon G, Khan MA, Hoag SW, Polli J, Raju GK, et al. Understanding pharmaceutical quality by design. AAPS J 2014;16:771-83.

3. Zhang L, Mao S. Application of quality by design in the current drug development. Asian J Pharm Sci 2017;12:1-8.

4. Grewal NK, Leadbeater NE. The central role of chemistry in 'quality by design' approaches to drug development. Future Med Chem 2012;4:1799-810.

5. Vogt FG, Kord AS. Development of quality-by-design analytical methods. J Pharm Sci 2011;100:797-812.

6. Hecht ES, Oberg AL, Muddiman DC. Optimizing mass spectrometry analyses: A tailored review on the utility of design of experiments. J Am Soc Mass Spectrom 2016;27:767-85.

7. Lyseng Williamson KA, Reynolds NA, Plosker GL. Tenofovir disoproxil fumarate: a review of its use in the management of HIV infection. Drugs 2005;65:413-32.

8. Pozniak A. Emtricitabine/tenofovir disoproxil fumarate: a viewpoint by anton pozniak. Drugs 2004;64:2083-4.

9. Nozza S, Poli A, Ripa M, Galli L, Chiappetta S, Spagnuolo V, et al Efficacy of elvitegravir/cobicistat/emtricitabine/eenofovir disoproxil fumarate as treatment for primary or recent HIV infection-authors' response. J Antimicrob Chemother 2017; 72:1549-50

10. Deeks ED, Perry CM. Efavirenz/emtricitabine/tenofovir disoproxil fumarate single-tablet regimen (Atripla $\left.{ }^{\circledR}\right)$ : a review of its use in the management of HIV infection. Drugs 2010;70:2315-38.

11. Clercq ED. A new drug combination therapy for treatmentnaive patients with HIV-1 infection, consisting of raltegravir, emtricitabine and tenofovir disoproxil fumarate. Expert Opin Pharmacother 2009;10:2935-7.

12. Gupta SK, Yeh E, Kitch DW, Brown TT, Venuto CS, Morse GD, et al. Bone mineral density reductions after tenofovir disoproxi fumarate initiation and changes in phosphaturia: a secondary analysis of ACTG A5224s. J Antimicrob Chemother 2017;72:2042-8.

13. Xu P, Wang Y, Qin Z, Qiu L, Zhang M, Huang Y. Combined medication of antiretroviral drugs tenofovir disoproxil fumarate, emtricitabine and raltegravir reduces neural progenitor cell proliferation in vivo and in vitro. J Neuroimmune Pharmacol 2017;12:682-92.

14. Mizushima D, Nguyen DTH, Nguyen DT, Matsumoto S, Tanuma $\mathrm{J}$, Gatanaga $\mathrm{H}$, et al. Tenofovir disoproxil fumarate coadministered with lopinavir/ritonavir is strongly associated with tubular damage and chronic kidney disease. J Infect Chemother 2018;24:549-54.

15. Yuen MF, Chen DS, Dusheiko GM, Janssen HLA, Lau DTY, Locarninim SA, et al. Hepatitis B virus infection. Nat Rev Dis Primer 2018;4:1-20.

16. Shaheen AA, Al Mattooq M, Yazdanfar S, Burak KW, Swain MG, Congly SE, et al. Tenofovir Ddisoproxil fumarate significantly decreases serum lipoprotein levels compared with entecavir nucleos $(\mathrm{t})$ ide analogue therapy in chronic hepatitis B carriers. Aliment Pharmacol Ther 2017;46:599-604.

17. Atul S, Charushila B, Surana Sanjay. Application of UVspectrophotometric methods of estimation of tenofovir disoproxil fumarate in tablets. Pak J Pharm Sci 2009;22:27-9. 
18. Al-Johar HI, Maher HM, Al-Zoman NZ, Al-Shammary DJ, AlShowiman HA. Stability-indicating capillary electrophoresis method for the determination of emtricitabine and tenofovir disoproxil fumarate in pharmaceutical tablets. Acta Chromatogr 2017;29:469-76.

19. Ramaswamy A, Arul Gnana Dhas AS. Development and validation of an analytical method for the quantitation of emtricitabine tenofovir, efavirenz-based on HPLC. Arab J Chem 2018;11:275-81.

20. Zhang Z, Wang L, Xu X, Dong Y, Zhang L. Development of a validated HPLC method for the determination of tenofovir disoproxil fumarate using a green enrichment process. Anal methods 2015;7:6290-8.

21. Dutta Tejaswi JK, Rajan RG. Reverse-phase high-performance liquid chromatography method development and validation for simultaneous estimation and forced degradation studies of emtricitabine, rilpivirine, and tenofovir alafenamide in solid dosage form. Asian J Pharm Clin Res 2019;12:112-6.

22. Babu C, Devanna N, Reddy KVS. Validated gradient stability indicating rp-hplc method for the simultaneous quantification of 11 related substances in the combined dosage forms of lamivudine and tenofovir disopeoxil fumarate. Int J Appl Pharm 2017;9:61-8.

23. PRNL, PP, Sk M, NR, Rao M, VB. UPLC separation analysis of emtricitabine, tenofovir, cobicistat and elvitegravir from their degradation products. Int J Pharm Pharm Sci 2016;8:362-9.

24. BVP, Reddy T, VB, YS, DR. Simultaneous determination of antiretroviral drugs emtricitabine and tenofovir desoproxil fumarate by stability indicating RP-HPLC method. Int J Pharm Pharm Sci 2015; 7:390-8.

25. Meesters RJW, Van Kampen JJA, Scheuer RD, Van der Ende ME Gruters RA, Luider TM. Determination of the antiretroviral drug tenofovir in plasma from HIV-infected adults by ultrafast isotope dilution MALDI-triple quadrupole tandem mass spectrometry. J Mass Spectrom 2011;46:282-9.

26. Illamola SM, Valade E, Hirt D, Dulioust E, Zheng Y, Wolf JP, et al. Development and validation of a LC-MS/MS method for the quantification of tenofovir and emtricitabine in seminal plasma. J Chromatogr B 2016;1033:234-41.

27. Barreiros L, Cunha Reis C, Silva EMP, Carvalho JRB, Das Neves I Sarmento B, et al. Development and validation of a liquid chromatography-MS/MS method for simultaneous quantification of tenofovir and efavirenz in biological tissues and fluids. J Pharm Biomed Anal 2017;136:120-5.
28. Ocque AJ, Hagler CE, Morse GD, Letendre SL, Ma Q. Development and validation of an LC-MS/MS assay for tenofovir and tenofovir alafenamide in human plasma and cerebrospinal fuid. J Pharm Biomed Anal 2018;156:163-9.

29. Valluru RK, B PB, S KS, V PK, Kilaru NB. High throughput LCMS/MS method for simultaneous determination of tenofovir, lamivudine and nevirapine in human plasma. J Chromatogr B 2013;931:117-26.

30. Kurmi M, Golla VM, Kumar S, Sahu A, Singh S. Stability behavior of antiretroviral drugs and their combinations. 1: Characterization of tenofovir disoproxil fumarate degradation products by mass spectrometry. RSC Adv 2015;5:96117-29.

31. Kenett RS, Kenett DA. Quality by design applications in biosimilar pharmaceutical products. Accreditation Qual Assur 2008;13:681-90.

32. Charoo NA, Ali AA. Quality risk management in pharmaceutical development. Drug Dev Ind Pharm 2013;39:947-60.

33. Hibbert DB. Experimental design in chromatography: a autorial review. J Chromatogr B 2012;910:2-13.

34. ICH Harmonised tripartite guideline, validation of analytical procedures: Text and Methodology Q2(R1); 2005.

35. Sirisha T. Bio-analytical liquid chromatographic determination of some selected chiral drugs in pharmaceutical dosage forms [dissertation on the internet]. Mysuru: JSS University. Available from: https://shodhganga.inflibnet.ac.in/handle/10603/176394 [Last accessed on 15 Oct 2018]

36. ICH Harmonised Tripartite Guideline, Stability testing of new drug substances and products Q1A(R2); 2003.

37. FDA, Guidance R. Validation of chromatographic methods center for drug evaluation and research (CDER), Food and Drug Administration; 1994.

38. Government of India, Ministry of Health. Pharmacopoeia of India; 2018.

39. National Center for Biotechnology Information [Internet]. PubChem Compound Database. Available from: https://pubchem.ncbi.nlm.nih.gov/compound/464205. [Last accessed on 10 Feb 2019]

40. Rao NM, Sankar DG. Development and validation of stabilityindicating HPLC method for simultaneous determination of lamivudine, tenofovir, and dolutegravir in bulk and their tablet dosage form. Future J Pharm Sci 2015;1:73-7. 